\title{
Autoconcepto, autoeficacia y conductas sexuales de riesgo en adolescentes ${ }^{10}$
}

\author{
Linda Teresa Orcasita \\ Mg. Familia \\ Pontificia Universidad Javeriana Seccional Cal \\ Departamento de Ciencias Sociales \\ Grupo de investigación Bienestar, \\ Trabajo, Cultura y Sociedad \\ Correo electrónico: Itorcasita@ \\ javerianacali.edu.co \\ Jennifer Andrea Mosquera Gil \\ Psicóloga \\ Pontificia Universidad Javeriana Seccional Cal \\ Departamento de Ciencias Sociales \\ Grupo de investigación Bienestar, \\ Trabajo, Cultura y Sociedad \\ Correo electrónico: jenniandre07@hotmail.com \\ Tatiana Carrillo González \\ Psicóloga \\ Pontificia Universidad Javeriana Seccional Cali \\ Departamento de Ciencias Sociales \\ Grupo de investigación Bienestar, \\ Trabajo, Cultura y Sociedad \\ Correo electrónico: tatianacarrillo01@hotmail.com
}

Recibido: 22/02/2017

Evaluado: $11 / 08 / 2017$

Aceptado: 20/03/2018

\section{Resumen}

En las últimas décadas se observa un incremento de comportamientos sexuales de riesgo que afectan directamente la salud y bienestar, esta tendencia se manifiesta en mayor proporción en la población adolescente, teniendo en cuenta las características propias de esta etapa. El objetivo del presente estudio fue establecer relaciones entre autoeficacia, autoconcepto y conductas sexuales de riesgo en adolescentes entre los 14 y 18 años de edad, de la ciudad de Cali; se llevó a cabo una investigación de carácter no experimental de tipo descriptivo - correlacional de corte trasversal. Participaron 133 adolescentes. Se evidenció que tanto autoconcepto como autoeficacia funcionan como factores protectores para evitar conductas de riesgo para la salud y como factor que impulsa a la búsqueda de comportamientos que beneficien la misma, en este caso, conductas sexuales de riesgo. Teniendo en cuenta esto, el adolescente, al presentar un índice alto de las variables mencionadas anteriormente, puede llegar a optar y poner en práctica conductas preventivas en el ejercicio de su sexualidad.

Palabras clave

Adolescencia, conducta sexual, riesgo, autoconcepto, autoeficacia.

10 Para citar este artículo: Orcasita, L.T., Mosquera, J.A., \& Carrillo, T. (2018). Autoconcepto, autoeficacia y conductas sexuales de riesgo en adolescentes. Informes Psicológicos, 18(2), pp. 141-168 http://dx.doi.org/10.18566/infpsic. v18n2a08 


\section{Self-concept, self-efficacy and risky sexual behavior in adolescents}

Abstract

In recent decades there has been an increase in risky sexual behaviors that directly affect the health and wellbeing. This trend is present in a greater proportion in the adolescent population, taking into account the characteristics of this stage. The aim of the study was to establish relationships between self-efficacy, self-concept and risky sexual behaviors in adolescents between 14 and 18 years old, from the city of Cali. se llevó a cabo una investigación de carácter no experimental de tipo descriptivo - correlacional de corte trasversal. A non-experimental cross-sectional descriptivecorrelational study was carried out, with the participation of 133 adolescents. It was evidenced that both self-concept and self-efficacy work as protective factors to avoid risky behaviors for health and as a factor that drives the search for behaviors that benefit it, in this case, risky sexual behaviors. Bearing this in mind, the adolescent, who presents a high index of the variables mentioned above, may opt and put into practice preventive behaviors in the exercise of their sexuality.

Keywords

Adolescence, sexual behavior, risk, self-concept, self-efficacy.

\section{Autoconceito, auto eficácia e condutas sexuais de risco em adolescentes}

Resumo

Nas últimas décadas tem-se observado um acréscimo de comportamentos sexuais de risco que atingem diretamente a saúde e o bem-estar. Tal tendência manifesta-se em proporção maior na população adolescente, levando em conta as caraterísticas próprias desta etapa. 0 objetivo deste estudo foi estabelecer relações entre auto-eficácia, autoconceito e condutas sexuais de risco em adolescentes entre os 14 e 18 anos de idade na cidade de Cali; foi executada uma pesquisa de caráter não experimental de tipo descritivo - correlacional de tipo descritivo - correlacional de corte transversal. Tomaram parte 133 adolescentes. Evidenciou-se que autoconceito assim como autoeficácia funcionam como fatores protetores para evidenciar as condutas de risco para a saúde e como fatores que impulsionam a procura de comportamentos que beneficiarem a mesma, neste caso, condutas sexuais de risco. Levando em conta isto todo, 0 adolescente, ao apresentar um alto índice das variáveis mencionadas com anterioridade, pode chegar a optar por, e implementar condutas preventivas no exercício da sua sexualidade. 


\section{ntroducción}

Actualmente, el autoconcepto y la autoeficacia son importantes para el desarrollo de conductas de autocuidado y protección durante la adolescencia. Las investigaciones señalan que estos aspectos motivan al individuo en la búsqueda de comportamientos que benefician su salud. Los hábitos saludables se empiezan a formar en la niñez y se consolidan en la adolescencia. De esta manera, se estima que las conductas y hábitos que se crean en esta etapa de la vida serán más difíciles de modificar en la adultez (Balaguer, García \& Pastor, 2006; Bandura, 1999; Corrales, Piña \& Rivera, 2008; Gálvez, Garrosa \& Moreno, 2005; Sánchez, 2006).

En Colombia, las cifras revelan que cada vez aumentan en mayor medida los embarazos a temprana edad y las infecciones de transmisión sexual [ITS] en adolescentes y jóvenes, lo cual conlleva a la necesidad de abordar los comportamientos de riesgo frente a las prácticas sexuales, fortaleciendo intervenciones orientadas al autocuidado y fortalecimiento de la autoeficacia. Se considera conductas de riesgo a toda situación en donde una persona se expone a la probabilidad de ocasionar daños a su salud o a la de quienes le rodean. En este caso, la exposición a la probabilidad de contraer una ITS o el Virus de Inmunodeficiencia Humana [VIH] (Castellá, Carlotto \& Gonçalves, 2007).

Algunas de las consecuencias ocasionadas por la no utilización de medidas de prevención en el comportamiento sexual son la presencia de las ITS o los embarazos a temprana edad, principalmente en los adolescentes, teniendo en cuenta que durante esta etapa ocurre en mayor medida el inicio de relaciones sexuales (Orcasita \& Uribe, 2009). Según las estimaciones del Programa conjunto de las Naciones Unidas sobre el VIH (ONUSIDA, 2010), a nivel mundial, alrededor de 33 millones de personas vivían con $\mathrm{VIH}$; y se considera que el $50 \%$ de las infecciones por $\mathrm{VIH}$ se dan alrededor de los 15 a los 24 años de edad, continuando estas cifras en aumento. Las investigaciones revelan que la autoeficacia y un mayor autoconcepto se pueden convertir en factores de protección frente al ejercicio de la sexualidad (Antón \& Espada, 2009; Bermúdez, Buela-Casal \& Teva, 2007; Uribe, Vergara \& Barona, 2009).

La autoeficacia y el autoconcepto son características y variables de la personalidad que se encuentran estrechamente ligadas al modo en que los adolescentes viven de una manera saludable o, por el contrario, incurren en conductas de riesgo (Goñi, Rodríguez y Ruiz, 2006), destacándose como la base de la seguridad y la confianza de sí mismo. Además, están relacionados con el amor propio, tienen relación con la percepción de sí mismo, ante los demás y ante las situaciones, abarcando qué tanto una persona cree y se acepta como es (Gálvez et al., 2005). La manera en que una persona se siente en relación consigo misma afecta todos los aspectos de la experiencia tanto en el amor y la amistad, como en la familia, la pareja y la comunidad.

Por un lado, el autoconcepto es comprendido como el componente cognitivo definido como la opinión que se tiene de la propia personalidad y sobre la propia 
conducta (Alcántara, 1995). Así, se trata de una creencia y opinión sobre sí mismo que determina el modo en que es organizada, codificada y usada la información que llega sobre la persona, además de un marco de referencia a través del cual se le da significado a la información sobre sí mismo y sobre los demás (Alcántara, 1995) y también se involucran componentes emocionales, sociales, físicos y académicos. En este sentido, el autoconcepto podría entenderse como la forma en que cada persona se valora y evalúa a sí misma (Mruk, 1999; Urquijo, 2002), por lo que tener un autoconcepto positivo ayuda a aceptar desafíos, a no tener miedo de desarrollar habilidades, a arriesgarse y a probar cosas nuevas. En cambio, un autoconcepto negativo genera falta de confianza en sí mismo, bajo rendimiento académico y social, una visión distorsionada de sí mismo y de los demás, y una vida personal infeliz (Urquijo, 2002).

En este orden de ideas, el autoconcepto es un factor positivo de protección que ayuda a incrementar las conductas saludables y disminuir factores de riesgo (Gálvez et al., 2005). Algunas investigaciones señalan que existe relación entre el autoconcepto, el consumo de SPA y la conducta sexual de riesgo (Balaguer et al., 2006; Barona et al., 2009; Gálvez et al., 2005). De esta manera, puede funcionar como factor protector para evitar conductas que puedan ser perjudiciales para la salud del individuo.

Con respecto a la autoeficacia, en la actualidad es considerada como una variable de gran interés en los procesos relacionados con la salud de las personas por los beneficios que proporcionan las estrategias de autocuidado. Se considera que es primordial en la reducción de riesgo frente a la infección por VIH y también para la evaluación en la prevención de la misma (Barona et al., 2009; Uribe, 2005). La autoeficacia es un constructo global que hace referencia a la creencia estable de la gente sobre su capacidad para manejar adecuadamente una amplia gama de estresores de la vida cotidiana (Bermúdez, Pérez, \& Suarez, 2000). Velázquez (2009) la define como un proceso metacognitivo que está relacionado con: las elecciones y toma de decisiones, gastos de energía física y mental, patrones de pensamiento y reacciones emocionales. Bandura (1977; 1987) propone que el comportamiento no es regulado por sus consecuencias inmediatas sino por las expectativas de eficacia, la convicción de que se puede tener éxito en los comportamientos requeridos para alcanzar los resultados esperados. Este mismo autor enfatizó que es importante distinguir entre expectativa de autoeficacia y expectativa de resultados. Las personas pueden creer que cierto comportamiento dará lugar a un resultado deseado, pero puede que no se sientan capaces de conseguir realizar este comportamiento (Bandura, 1977). La expectativa de autoeficacia puede influir tanto en sentimientos como pensamientos y acciones. Las personas con pocas expectativas tienden a mostrar sentimientos negativos sobre sus capacidades.

En cuanto a los pensamientos, la percepción de autoeficacia facilita las cogniciones referidas a las habilidades propias, actuando estos pensamientos como motivadores de la acción. Las personas que se sienten eficaces eligen tareas más desafiantes, se ponen metas más altas y persisten más en sus propósitos (Bermúdez et al., 2000). De este modo, la autoeficacia tiene que ver con el modo como 
la persona actúa, piensa y se comporta, influyendo en el establecimiento y ejecución de metas y conductas que intentará cumplir, y cómo se enfrenta a los contratiempos (Sánchez, 2006).

La autoeficacia juega un papel central en la autorregulación de la conducta con base a los efectos sobre la formación e intensidad frente a los obstáculos. Es uno de los mejores elementos que ayuda a predecir las intenciones que tiene un sujeto para llevar a cabo una conducta saludable teniendo influencia en la conducta de riesgo sexual (Sánchez, 2006).

Bandura (1999) también señala que "los hábitos saludables que se mantienen durante toda la vida se forman en la infancia y adolescencia" (p. 45). Por ello es importante que los niños y adolescentes aprendan destrezas de automanejo para así evitar la adquisición de una ITS o de un embarazo prematuro. Se ha hallado relación con la conducta sexual de riesgo al establecer que aquellos adolescentes que no emplean el condón o no exigen su uso a la pareja sexual tienen baja autoeficacia, debido a que varios de estos estudios han hallado que los adolescentes poseen un amplio conocimiento sobre cómo contraer una ITS, sin embargo, no ponen en práctica lo que dicen (Andrade et al., 2006; Barona et al., 2009; Enríquez et al., 2007; Sánchez, 2006; Uribe \& Orcasita, 2009).

A nivel internacional, Antón et al. (2008) señalan que el consumo de sustancias psicoactivas es otro factor que incrementa el aumento de riesgo durante las relaciones sexuales en jóvenes españoles. Dentro de esas sustancias, se encuentra el alcohol, que está relacionado con el no uso del condón, el cual genera mayor susceptibilidad debido a que contiene propiedades de desinhibición que aumentan la probabilidad de realizar una conducta de riesgo. Las investigaciones señalan que el $23.8 \%$ de los adolescentes consumen alcohol antes de la relación sexual, el $6 \%$ durante la relación sexual y el 1.2\% después (Antón et al., 2008); de esta forma, existe mayor probabilidad de contraer VIH/SIDA, una ITS o quedar en embarazo. EI VIH/SIDA se ha extendido por el mundo entero convirtiéndose en uno de los principales problemas de salud pública (Andrade et al., 2006; Ballester et al., 2007; Enríquez et al., 2007).

La OMS (2011) ha manifestado su preocupación por el aumento de las ITS en adolescentes, debido a que cada año más del 15\% contrae una ITS; cerca de 560.000 adolescentes entre 15 y 24 años de edad viven con VIH/SIDA. En España se han reportado más de 76.386 casos de SIDA, donde muchos han adquirido la infección desde la adolescencia (Ministerio de Sanidad y Consumo, citado por Antón et al., 2008). Estos mismos autores dicen que España es el país con mayores casos reportados de VIH/SIDA. Bermúdez et al. (2007) señalan que el 2.5 de los adolescentes no sabe qué es una ITS, el 2.8 había tenido una ITS en los últimos 12 meses y el $81.4 \%$ usaron anticonceptivo durante su última relación sexual. Por otro lado, en Estados Unidos, cerca de 750 mil adolescentes se embarazan anualmente, 20 mil jóvenes son infectados por el VIH y se presentan cerca de 4 millones de nuevos casos de ITS entre jóvenes de 15 a 19 años (Feijoo, 2004).

En Colombia, se ha encontrado que "los hombres inician su vida sexual a los 13.4 años de edad en promedio y las mujeres a los 14.8 años de edad; éstas 
tienen su primer hijo alrededor de los 16.2 años de edad" (Orcasita \& Uribe, 2009, p. 5). Los adolescentes sexualmente activos, en su mayoría no usan métodos anticonceptivos aun cuando han recibido información sobre estos; también se encontró que continúan usando métodos ineficaces como el coitus interruptus (Argote, Castillo, Mejía, Vásquez, \& Villaquirán, 2005). En otro estudio se encontró que el $38.6 \%$ de los adolescentes no usan condón en la primera relación sexual (Ceballos \& Campo, citados por Ballester et al., 2007). Algunas de las razones por las que los jóvenes manifiestan que no usan condón son: escepticismo respeto a la eficacia, creencias sobre sus efectos secundarios, ideas de que el condón solo debe usarse con mujeres que no son vírgenes, pérdida de sensibilidad, entre otras (Ballester et al., 2007), estos son aspectos importantes para el desarrollo de la presente investigación y las variables objeto de estudio.

Según la ENDS (2010), el 20.1\% de los adolescentes vallecaucanos usan algún método de planificación familiar, el 6.2\% usa el condón masculino, el 2.9\% usa métodos tradicionales, el $6.5 \%$ de las mujeres usan el condón masculino y el 30\% de los adolescentes manifiestan haber dejado de usar el condón, único método que previene las ITS, porque consideran que es costoso e incómodo de usar. Sin embargo, solo el $11.9 \%$ se considera en riesgo de contraer una ITS o $\mathrm{VIH}$ y el $21.7 \%$ de los jóvenes no conoce sobre las ITS. En Cali, el $61.4 \%$ de los hombres inician su vida sexual entre los 12 y los 16 años, y el $44.5 \%$ de las mujeres lo hacen entre los 15 y los 17 años (Secretaría de Salud Pública Municipal, 2004). El uso de anticonceptivos entre la primera y última relación sexual, en adolescentes, ha disminuido. Entre el $13 \%$ y $20 \%$ no usan ningún tipo de anticonceptivo en su primera relación sexual, pese que los adolescentes manifiestan tener conocimiento de ITS, no lo reflejan en el momento de tener relaciones sexuales (Orcasita \& Uribe, 2009).

Así, el uso inconsistente del condón tiene como predictores variables psicosociales como la autoeficacia (Moreno, Piña \& Robles, 2006). Lo que quiere decir que el éxito que se obtenga en la educación sexual sobre ITS dependerá en gran medida de la capacidad para cambiar comportamientos en cuanto a las prácticas sexuales de riesgo (Barona et al., 2009). Debido a la prevalencia de las ITS, el contacto genital o el tener relaciones sexuales constituyen una conducta de riesgo para cualquier persona en caso de que no tome las medidas preventivas necesarias. El no tomar estas medidas al momento de tener contacto genital con otra persona se considera una conducta sexual de riesgo (Ballester et al., 2007; Castellá et al., 2007). Ésta ha sido asociada a diferentes factores incluyendo los psicosociales, entre ellos la autoeficacia y el autoconcepto.

Una investigación de Goñi et al. (2006), con 539 estudiantes de diferentes instituciones educativas entre los 12 y 23 años de edad, donde se buscaba identificar las relaciones que hay entre autoconcepto, bienestar psicológico y distintas variables de la salud como el consumo de alcohol y tabaco y la realización de actividad física, concluyó que el autoconcepto positivo va de la mano con hábitos de vida saludables. Resultados similares a los obtenidos por Balaguer et al. (2006), quienes concluyeron que los jóvenes con bajo autoconcepto tienen comportamientos de riesgo para la salud. También en España, 
realizaron un estudio con 4.456 adolescentes con el propósito de analizar si existen en adolescentes diferencias en conductas de riesgo para la infección por el $\mathrm{VIH}$ y las ITS de acuerdo al tipo de centro educativo (público/privado o concertado), el sexo y la edad. Dicho estudio descriptivo concluyó que existen diferencias en conductas de riesgo para la infección por $\mathrm{VIH}$ determinadas por las variables sociodemográficas (Bermúdez et al., 2007).

Con el propósito de determinar los comportamientos de riesgo para la salud en estudiantes recién ingresados a una universidad privada en la ciudad de Barranquilla fue realizado un estudio descriptivo con 540 estudiantes, donde se concluyó que las conductas de riesgo son prevalentes y tienen influencia para la salud a corto y largo plazo (Alcalá, Alonso, Consuegra, Lubo, \& Pérez, 2007). También Ballester et al. (2007) realizaron un estudio descriptivo exploratorio de corte transversal, con 300 adolescentes, 150 mujeres y 150 hombres entre los 16 y 18 años de edad, de la ciudad de Medellín. Su objetivo fue estudiar el comportamiento sexual frente a la infección del VIH. Como resultados hallaron que los adolescentes tienen vacíos conceptuales frente al VIH y el SIDA, lo cual se considera como un factor que aumenta la probabilidad de riesgo. Asimismo, en Bogotá fue llevado a cabo un estudio con el propósito de evaluar el impacto de la presencia de padres, madres y docentes en un programa de educación sexual teniendo en cuenta las variables de la dimensión psicológica de promoción y la prevención como son el riesgo percibido, la autoeficacia y las normas subjetivas acerca de las ITS y los embarazos a temprana edad y no planeados en adolescentes de dicha ciudad. La investigación tuvo como resultado que la presencia de padres, madres y docentes dentro del programa es más efectiva en el incremento de riesgo percibido de los adolescentes para la adquisición de ITS y embarazos a temprana edad (Gómez, 2009).

Otra investigación desarrollada en Cali por Orcasita y Uribe (2009), con 197 estudiantes jóvenes universitarios, encontró que las principales conductas de riesgo que exponen a los jóvenes a adquirir una ITS son: el inicio de las relaciones sexuales tempranas, consumo de sustancias psicoactivas antes y durante la relación sexual, no utilización del preservativo y el número de parejas sexuales a lo largo de la vida.

Teniendo en cuenta los estudios mencionados anteriormente, la autoeficacia y el autoconcepto son variables que han sido relacionadas con las conductas de riesgo y la vivencia con que la persona experimenta su vida (Goñi et al., 2006). El no uso del condón, es una característica que ha sido asociada al autoconcepto, autoeficacia y autocuidado porque se encuentran vinculadas a la estabilidad emocional, responsabilidad y compromiso que se debe tener con la propia salud (Bojanini \& Gómez, 2004). Se encontró como aspecto común en los estudios, un factor psicosocial que media en la conducta de riesgo social que tiene que ver con la autoeficacia y el autoconcepto.

Asimismo, los estudios evidencian que los adolescentes manejan conocimientos sobre el VIH/SIDA, sin embargo, no es suficiente para que adopten conductas de protección (Corrales et al., 2008). Específicamente en Colombia, los estudios resaltan que los adolescentes inician relaciones sexuales a temprana edad y adoptan 
diversas conductas de riesgo como el escaso uso del preservativo y de otros métodos anticonceptivos, debido a la percepción de invulnerabilidad y riesgo que tienen estos (Argote et al., 2005; Ballester et al., 2007; Barona et al., 2009; Secretaría de Salud Municipal, 2004), sumado a los conocimientos insuficientes en los temas de salud sexual y reproductiva. Además, los autores relacionan que dentro de los factores que influyen en la adopción de estas conductas de riesgo se encuentran las variables de personalidad como la autoeficacia y el autoconcepto (Antón et al., 2008; Balaguer et al., 2006; Barona et al., 2009; Goñi et al., 2006; López \& Moral, 1999; Moreno et al., 2006).

La revisión realizada evidencia que, aunque existen diversos estudios centrados en la identificación de conductas sexuales de riesgo en la población colombiana, no se encuentran suficientes estudios en Cali que profundicen la relación con las variables de autoconcepto y autoeficacia, teniendo en cuenta la importancia que tienen en la práctica sexual durante esta etapa del desarrollo. Tales factores son evidencia de la necesidad de abordar las conductas sexuales de riesgo que viven algunos adolescentes, en donde la influencia del autoconcepto y la autoeficacia se constituyen en aspectos fundamentales para el manejo y abordaje de los hábitos de autocuidado que se consolidan en esta etapa del ciclo vital. Como objetivo general, el presente estudio se propuso establecer relaciones entre autoeficacia, autoconcepto y conductas sexuales de riesgo, en adolescentes entre los 14 y 18 años, a través de los cuales se describieron las principales conductas sexuales de riesgo que reportan estos, se identificaron los niveles de autoeficacia y autoconcepto en la muestra poblacional del estudio $\mathrm{y}$, por último, se realizaron correlaciones entre autoeficacia, autoconcepto y conductas sexuales de riesgo en función de variables sociodemográficas.

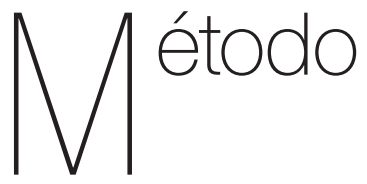

La investigación que se llevó a cabo fue no experimental de tipo descriptivocorrelacional, de corte transversal (León \& Montero, 2005).

\section{Participantes}

La muestra de este estudio correspondió a 133 adolescentes, mujeres y hombres, escolares de secundaria, con edades comprendidas entre los 14 y 18 años de edad. Se realizó un muestreo no probabilístico (Hernández et al., 2006).

\section{Instrumentos}

Se utilizaron tres instrumentos para la medición de las variables conducta sexual de riesgo, autoeficacia y autoconcepto, a saber: (1) Cuestionario Confidencial sobre Vida Sexual Activa (CCVSA) diseñado por el Ministerio de Salud de Colombia (1997), para obtener información acerca de la realización de determinadas conductas sexuales. El cuestionario consta de 27 preguntas, las iniciales recogen información sociodemográfica de los participantes (edad, sexo, estado civil, curso y estatus 
socioeconómico) y las demás preguntas están orientadas a puntualizar sobre las relaciones sexuales (vaginal, bucogenital y anal), el uso del preservativo, el número de parejas sexuales, el consumo de sustancias psicoactivas en las relaciones sexuales, las formas de prevenir la infección por $\mathrm{VIH}$ y la prueba de diagnóstico del VIH. Se confirma un análisis de confiabilidad con un alfa de cronbach de .66 para el instrumento. (2) Escala de Autoconcepto Forma-5 (AF5), elaborado por García y Musitu (1995), que evalúa el autoconcepto en adolescentes por medio de 36 ítems con tres opciones de respuesta: siempre, algunas veces y nunca. A mayor puntuación en cada uno de los factores mencionados, corresponde mayor autoconcepto en dicho factor. La evaluación incluye cuatro contextos: el contexto académico (11 ítems), el contexto social (5 ítems), el contexto emocional ( 9 ítems) y el contexto familiar (6 ítems); adicionalmente incluyen 5 ítems que no tienen clasificación. Bérmudez et al. (2005) realizaron una adaptación al contexto colombiano de la escala. Adicionalmente se realizó un análisis factorial que confirma la estructura de la escala y un análisis de confiabilidad con un alfa de cronbach .70 para el instrumento en general. (3) Escala de Autoeficacia Generalizada (EAG) elaborada por Jerusalem y Schwarzer en 1992, la cual evalúa la creencia de autoeficacia del examinado frente a determinadas situaciones de la vida; consta de 10 ítems tipo Liker de cuatro puntos. Ha sido traducida a más de 25 idiomas y utilizada en muchos estudios; ha alcanzado una buena consistencia interna (Alfa de Cronbach entre .79 y .93) y alto grado de validez; en este estudio se utilizó la versión en español de Baessler y Schwarzer (1996).

\section{Procedimiento}

En primera instancia se realizó el contacto con las instituciones educativas, explicándoles los propósitos, objetivos y procedimientos relacionados con la investigación; también se les informó sobre el contenido de los instrumentos, así como la duración de dicha aplicación. Posteriormente, se diligenciaron el consentimiento y asentimiento informado por parte de los acudientes legales de los estudiantes seleccionados y se inició el proceso de aplicación de los instrumentos. La aplicación osciló entre 30 a 40 minutos. Finalmente, se procedió a realizar el análisis de los datos por las investigadoras a través del Statiscal Package for Social Sciences (SPSS) versión 17.0 para Windows.

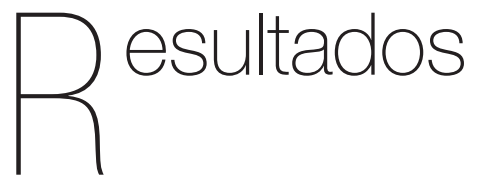

Se obtuvo información de 133 adolescentes, de los cuales el 35.3\% son hombres y el $64.7 \%$ son mujeres. Estos adolescentes presentaron distribución perfectamente homogénea por escolaridad. El 27.2\% de los adolescentes son de estrato 1 , el $70.4 \%$ de estrato 2 y el restante de estrato 3 (2.4\%). La tabla 2 muestra algunos estadísticos descriptivos para la edad de los adolescentes estudiados, se observa que se obtuvo un rango de edad entre 14 y 18 años, con un promedio de 16.4 años y una desviación estándar de 1.4 años. 
Tabla 1.

Estadísticos descriptivos para la edad de los adolescentes estudiados

\begin{tabular}{ccccc}
\hline & Mínimo & Máximo & Media & Desv. típ. \\
\hline \multirow{2}{*}{ Edad } & 14 & 18 & 16.16 & 1.126 \\
\hline
\end{tabular}

El $43.2 \%$ de los adolescentes viven con su padre y madre, el 33.3\% vive con su madre, mientras que un $25.8 \%$ vive también con otros familiares diferentes a sus padres. Sólo un 5.3\% vive con el padre y en igual porcentaje vive con otras personas distintas al núcleo familiar. De acuerdo a los objetivos, en la primera fase descriptiva se analizaron por medio de tablas de frecuencia y por medio de medidas de tendencia central y dispersión. Aquí también se describieron las puntuaciones arrojadas por las escalas de autoconcepto y autoeficacia utilizadas. Con referencia al tamaño de la muestra, al tipo de medida de las variables de interés y la distribución se procedió a desarrollar el coeficiente de correlación de Spearman para identificar el nivel de correlación entre las variables de autoconcepto y autoeficacia. Posteriormente, se realizó un análisis estadístico de los componentes principales el cual permitió caracterizar a los adolescentes en cuanto al nivel de autoconcepto y autoeficacia, además permitió en un gráfico multidimensional representar las relaciones entre estas variables de estudio con las conductas sexuales de riesgo reportadas por los adolescentes. Las pruebas de Mann-Whitney y KruskalWallis permitieron comprobar si existían diferencias en el autoconcepto y autoeficacia en función de variables sociodemográficas y las conductas sexuales de los adolescentes.

\section{Conductas sexuales de los adolescentes}

De los adolescentes que participaron, el $59.4 \%$ ha tenido alguna vez una relación sexual vaginal, de los que el 21.1\% de los adolescentes ha practicado el sexo bucogenital (oral) y el $9.8 \%$ ha tenido sexo anal, como se observa en la Tabla 2.

Tabla 2

Alguna vez en su vida ha tenido relaciones sexuales

\begin{tabular}{ccc}
\hline & Frecuencia & Porcentaje \\
\hline Del pene a la vagina & 79 & $59.4 \%$ \\
Del pene a la boca & 28 & $21.1 \%$ \\
Del pene al ano & 13 & $9.8 \%$ \\
\hline
\end{tabular}

La edad media de inicio de relaciones sexuales en los adolescentes estudiados es de 13.5 años con una desviación típica de 2.2 años. Las medias y la desviación típica de la variable edad de inicio de las relaciones sexuales en función del sexo, la escolaridad y el estrato se muestran en la Tabla 3. Así, se observa que la edad de inicio de las relaciones sexuales más frecuente es la de 14 años, con un porcentaje del 20.5\%. También se evidencia que más del $13 \%$ de los estudiantes tuvieron su primera relación sexual antes de los 12 años y sólo el $17.8 \%$ de los adolescentes iniciaron su vida sexual después de los 15 años. Se evidencia que las mujeres inician su vida sexual después que los hombres (a los 15 años frente a los 12 años en los hombres). A través de la prueba no paramétrica de Mann-Whitney se comprobó una diferencia estadísticamente significativa ( $p$-valor < .05) y no se encontraron 
diferencias estadísticamente significativas en la edad de inicio de las relaciones sexuales en función de la escolaridad y el estrato socioeconómico, a través de la prueba no paramétrica Kruskal-Wallis (p-valor > .05) (Véase Tabla 4).

Tabla 3.

Medias y desviación típica de la edad de inicio de las relaciones sexuales de los adolescentes en función del sexo, la escolaridad y el estrato

\begin{tabular}{ccccc}
\hline & & Media & Desviación típica & p-valor \\
\hline \multirow{2}{*}{ Sexo } & Hombre & 12.2 & 2.1 & $.000^{*}$ \\
& Mujer & 15 & 1.4 & $.382^{\circ}$ \\
\hline \multirow{2}{*}{ Escolaridad } & Decimo & 13.9 & 1.4 & $.967^{\circ}$ \\
& Undécimo & 13.2 & 2.6 & \\
\hline \multirow{2}{*}{ Estrato } & Estrato 1 & 13.5 & 2.4 & \\
& Estrato 2 & 13.6 & 2.1 & \\
\hline
\end{tabular}

Nota: * prueba Mann-Whitney; ${ }^{\circ}$ prueba Kruskal-Wallis

Entre los adolescentes que han tenido relaciones sexuales, el $31.3 \%$ ha usado preservativos en su primera relación sexual comparado con un $68.8 \%$ que no lo usó. El uso de preservativos fue más frecuente en las mujeres que en los hombres, ya que casi la mitad de las mujeres usaron el preservativo, mientras que tan solo el 14\% de los hombres lo usaron; la prueba chi-cuadrado mostró una relación significativa entre el uso de preservativo y el sexo (p-valor $<.05)$, pero no evidenció una relación significativa entre el uso de preservativo y la escolaridad ( $p$-valor $>$.05) y el estrato ( $p$-valor $>$.05) (Véase Tabla 4). Por lo tanto, los hombres tienen una probabilidad mucho más alta de no usar preservativo en su primera relación sexual.

Tabla 4.

Frecuencia del uso de preservativos en la primera relación sexual en función del sexo, escolaridad y estrato

\begin{tabular}{ccccccc}
\hline & & \multicolumn{2}{c}{ Usó preservativo } & \multicolumn{2}{c}{ No usó preservativo } & p- valor* $^{*}$ \\
\cline { 3 - 7 } & & Frecuencia & Porcentaje & Frecuencia & Porcentaje & \\
\hline \multirow{2}{*}{ Sexo } & Hombre & 5 & 13.9 & 31 & 86.1 & .001 \\
& Mujer & 20 & 45.5 & 24 & 54.5 & .740 \\
\hline \multirow{2}{*}{ Escolaridad } & Decimo & 11 & 28.9 & 27 & 71.1 & 69.4 \\
& Undécimo & 11 & 30.6 & 25 & 58.8 & .556 \\
\hline \multirow{3}{*}{ Estrato } & Estrato 1 & 7 & 41.2 & 10 & 70.4 & \\
& Estrato 2 & 16 & 29.6 & 38 & 66.7 & \\
& Estrato 3 & 1 & 33.3 & 2 & & \\
\hline
\end{tabular}

Nota: * prueba Chi-cuadrado 
Durante los últimos 12 meses, el 83.8\% de los adolescentes tuvieron relaciones sexuales, el $93.7 \%$ de estas relaciones han sido vaginales, un $67.2 \%$ han sido bucogenitales y un $6.5 \%$ han sido anales. Cabe destacar que usaron el preservativo en el 55\% de los casos donde tuvieron relación sexual vaginal, en el $40.9 \%$ de los casos donde que tuvieron relaciones sexuales bucogenitales y el $66.7 \%$ de los adolescentes que tuvieron relaciones sexuales anales. Esto muestra que tan solo la mitad de los adolescentes usan preservativos en sus relaciones sexuales. Con relación a si en los últimos 12 meses ha tenido relaciones sexuales con la misma persona o con más de una, el 36.4\% de los adolescentes estudiados han tenido relaciones sexuales con más de una persona. Este porcentaje es mucho más superior en los hombres que en las mujeres, como se observa en la Figura 1. La prueba Chi-cuadrado mostro que existe una relación significativa entre estas dos variables, es decir, que los hombres tienen una mayor probabilidad de tener relaciones sexuales en el último año con más de una persona.

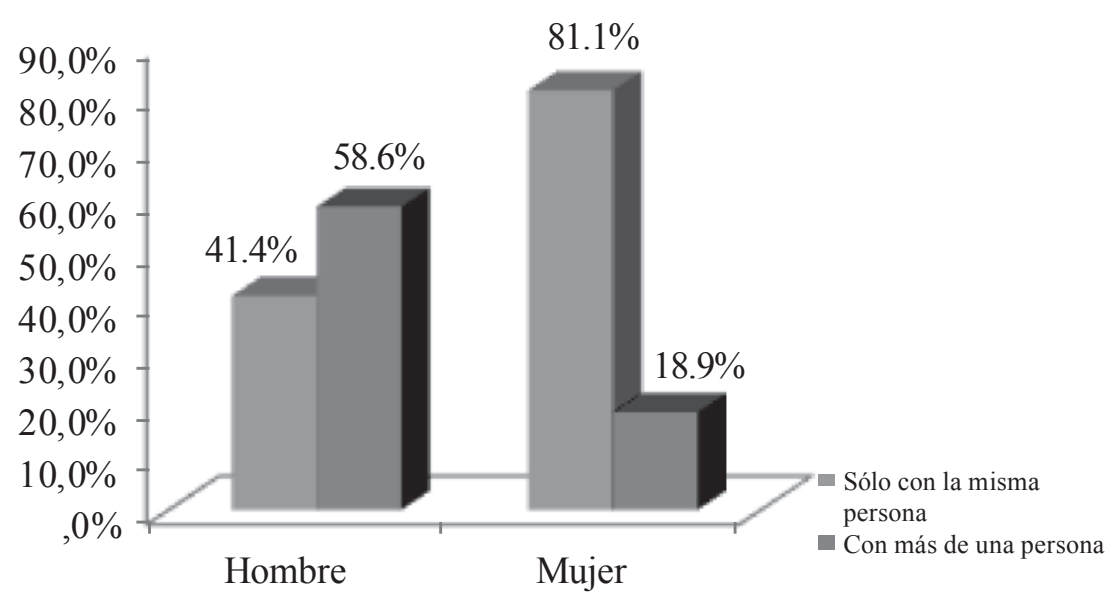

Figura 1. En los últimos 12 meses ha tenido relaciones sexuales con la misma persona o con más personas según el sexo

El promedio del número de personas diferentes con las cuales han tenido relaciones sexuales es de 2.5 personas con una desviación estándar de 1.5 personas. Este promedio es mayor en hombres (3.1 personas) que en mujeres (1.9 personas). El $87.1 \%$ de los adolescentes en los últimos 12 meses han tenido relaciones sexuales sólo con personas del otro sexo, el $10 \%$ con personas de su mismo sexo y el $2.8 \%$ con personas de ambos sexos, aspecto importante ya que inicialmente los adolescentes reportaban en su orientación sexual ser heterosexual. Solo el $44.6 \%$ de los adolescentes han usado el preservativo en su última relación sexual. Dentro de las principales razones por las cuales no han usado el preservativo son porque confían en la persona con quien tuvo la relación sexual (58.1\%), porque sólo tiene relaciones sexuales con esa persona (64.5\%), porque la personas con quien tuvo la relación le disgusta usarlo (35.5\%) y por el afán del momento (38.7\%). 
Tabla 5.

Razones por la cual los adolescentes estudiados no usaron el preservativo en su última relación sexual

\begin{tabular}{ccc}
\hline & Frecuencia & Porcentaje \\
\hline Porque a usted o a la persona con quien tuvo la relación le disgusta usarlo & 11 & 35.5 \\
Porque la persona con quien tuvo esa relación se negó a usarlo & 6 & 19.4 \\
Porque le resulto difícil hablar del uso de condón & 1 & 3.2 \\
Porque confía en la persona con quien tuvo la relación & 18 & 58.1 \\
Porque solo tiene relaciones sexuales con esa persona & 20 & 3.5 \\
Porque estaba bajo el efecto del alcohol o drogas & 1 & 9.7 \\
Porque era difícil conseguirlo en ese momento & 3 & 38.7 \\
Por el afán del momento & 12 & \\
\hline
\end{tabular}

Nota: * El participante podía marcar varias opciones de respuesta

Dentro de los adolescentes que han tenido relaciones sexuales en los últimos 12 meses con penetración del pene, el 69.3\% lo ha hecho bajo el efecto de alguna sustancia psicoactiva. De este grupo de adolescentes, el 83.3\% ha estado bajo el efecto del alcohol, el $8.3 \%$ bajo el consumo de marihuana, el $8.3 \%$ bajo el consumo de heroína y el $4.2 \%$ bajo el consumo de basuco, tranquilizantes, pastillas alucinógenas, pegante o inhalantes. Entre los comportamientos más importantes para evitar la infección por el VIH que han utilizado los adolescentes estudiados que han tenido relaciones sexuales se encuentran el ponerse de acuerdo sobre el uso de medidas de protección (69.2\%), usar el condón (60\%) y tener relaciones sexuales con la misma persona (58.5\%) o conversar sobre el riesgo de adquirir el virus (58.5\%), como se observa en la Figura 2.

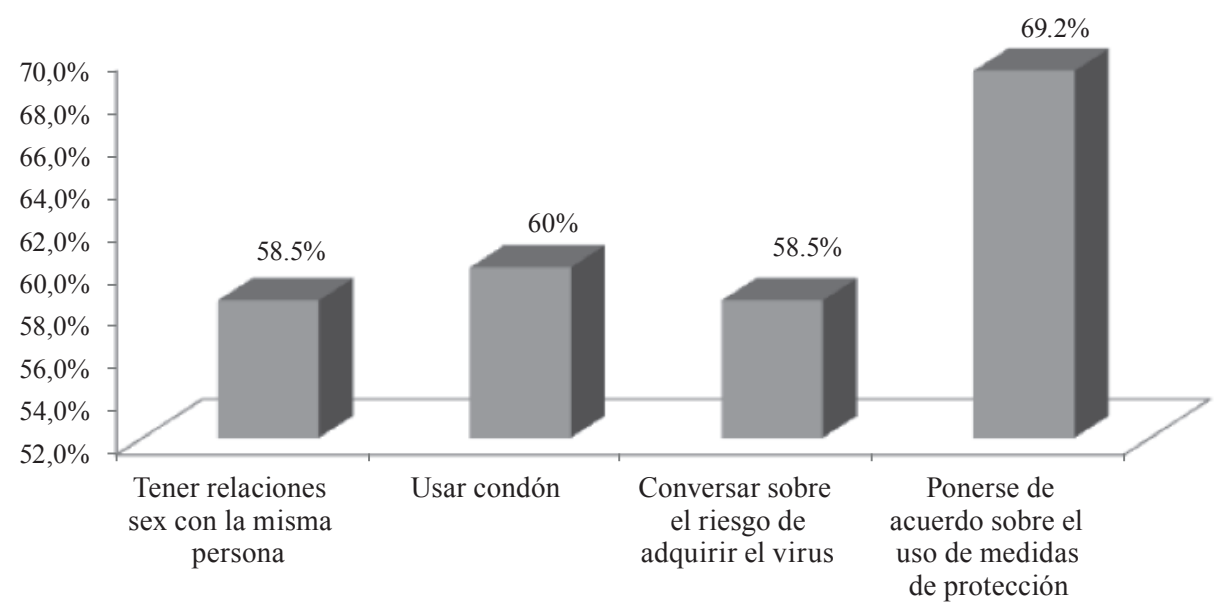

Figura 2. Comportamientos para evitar la infección por el VIH que reportan los adolescentes 
En cuanto al examen clínico para diagnosticar el VIH, solo el $19.4 \%$ de los adolescentes estudiados se han realizado la prueba de diagnóstico. De los adolescentes que se han realizado la prueba de $\mathrm{VIH}$, el 58.3\% recibió orientación antes de realizarse la prueba de diagnóstico del VIH. En el último año, el 1.5\% de los adolescentes afirma que sí ha tenido alguna enfermedad de transmisión sexual.

\section{Autoconcepto reportado por los adolescentes}

En la Tabla 6 se muestra una descripción de las subescalas del Cuestionario Autoconcepto Forma A. Se observan las puntuaciones promedio con su respectiva desviación típica, al igual que el puntaje mínimo y máximo, además del coeficiente de variación (CV) de las subescalas. Se encontró que la subescala Académico resultó ser la más homogénea, es decir, que los adolescentes tienen un autoconcepto en la parte académica muy similar entre ellos.
Tabla 6.

Estadísticos descriptivos para las subescalas del cuestionario de Autoconcepto Forma A

\begin{tabular}{cccccc}
\hline & Mínimo & Máximo & Media & $\begin{array}{c}\text { Desv. } \\
\text { típ. }\end{array}$ & CV \\
\hline Académico & 19 & 30 & 23.4 & 2.2 & $9.3 \%$ \\
Social & 5 & 11 & 7.6 & 1.4 & $18.3 \%$ \\
Emocional & 10 & 25 & 18.5 & 2.9 & $15.5 \%$ \\
Familiar & 6 & 18 & 14.6 & 2.3 & $15.7 \%$ \\
\hline Total & 54 & 77 & 64.2 & 4.5 & $7.1 \%$ \\
\hline
\end{tabular}

En la Tabla 7 se recogen las puntuaciones promedio y las desviaciones típicas de las subescalas del autoconcepto en función del sexo, la escolaridad y el estrato socioeconómico. Se evidencia que existe una diferencia estadísticamente significativa al nivel del 95\% en el factor emocional y autoconcepto en general en función del sexo, a través de la prueba no paramétrica de MannWhitney, por tanto, los hombres tienen un mejor autoconcepto emocional que las mujeres.

Tabla 7.

Estadísticos descriptivos para las subescalas del cuestionario de Autoconcepto Forma A en función del sexo, la escolaridad y el estrato

\begin{tabular}{|c|c|c|c|c|c|c|c|c|c|c|c|c|c|c|c|c|}
\hline & & \multicolumn{3}{|c|}{ Académico } & \multicolumn{3}{|c|}{ Social } & \multicolumn{3}{|c|}{ Emocional } & \multicolumn{3}{|c|}{ Familiar } & \multicolumn{3}{|c|}{ Autoconcepto } \\
\hline & & M & D.T. & $p^{*}$ valor & $M$ & DT & $p^{*}$ valor & $M$ & DT & $\mathrm{p}^{*}$ valor & $M$ & DT & $\mathrm{p}^{*}$ valor & M & DT & $\mathrm{p}^{\star}$ valor \\
\hline \multirow{2}{*}{ Sexo } & Hombre & 23.1 & 2.4 & \multirow{2}{*}{.643} & 7.4 & 1.4 & \multirow{2}{*}{.178} & $19.9^{*}$ & 2.9 & \multirow{2}{*}{.000} & 14.9 & 2.2 & \multirow{2}{*}{.328} & $65.4^{*}$ & 4.9 & \multirow{2}{*}{.001} \\
\hline & Mujer & 23.6 & 2 & & 7.8 & 1.4 & & $17.6^{*}$ & 2.5 & & 14.5 & 2.4 & & $63.4^{*}$ & 4.2 & \\
\hline \multirow{2}{*}{ Escolar. } & Décimo & 23.4 & 2 & \multirow{2}{*}{.578} & 7.8 & 1.5 & \multirow{2}{*}{.977} & 18.2 & 3 & \multirow{2}{*}{.550} & 14.5 & 2.5 & \multirow{2}{*}{.523} & 63.9 & 4.9 & \multirow{2}{*}{.528} \\
\hline & Undécimo & 23.4 & 2.4 & & 7.4 & 1.2 & & 18.8 & 2.8 & & 14.8 & 2.2 & & 64.4 & 4.2 & \\
\hline \multirow{3}{*}{ Estrato } & Estrato 1 & 23.8 & 1.9 & \multirow{3}{*}{.559} & 7.9 & 1.4 & & 18.7 & 2.5 & \multirow{3}{*}{.472} & 14.3 & 2.7 & & 64.7 & 4.1 & \multirow{3}{*}{.532} \\
\hline & Estrato 2 & 23.2 & 2.3 & & 7.6 & 1.4 & .503 & 18.6 & 3 & & 14.9 & 2.2 & .428 & 64.2 & 4.9 & \\
\hline & Estrato 3 & 23.7 & 1.5 & & 6.7 & .6 & & 16.3 & 5.9 & & 15.3 & .6 & & 62 & 5.3 & \\
\hline
\end{tabular}


En la Tabla 8 se muestran las correlaciones de Spearman entre las subescalas del cuestionario de Autoconcepto Forma A. Se observa que el factor emocional se relaciona positivamente con el factor familiar (rho = .215), sin embargo, la relación es débil, es decir, que a un mayor autoconcepto familiar mayor será el autoconcepto emocional. De otro lado, también se encontró una relación estadísticamente significativa entre el factor académico y el autoconcepto en general (rho $=.445)$, entre el factor social y el autoconcepto en general (rho = .185), entre el factor emocional y el autoconcepto en general (rho $=.624)$ y entre el factor familiar y el autoconcepto en general (rho $=.635)$.

Tabla 8.

Correlaciones de Spearman entre las subescalas del cuestionario de autoconcepto

\begin{tabular}{cccccc}
\hline & Académico & Social & Emocional & Familiar & Autoconcepto \\
\hline Académico & - & -.088 & -.066 & .095 & $.445^{*}$ \\
\hline Social & - & -.040 & -.082 & $.185^{\star}$ \\
\hline Emocional & & - & $.215^{*}$ & $.624^{*}$ \\
\hline Familiar & & & - & $.635^{*}$ \\
\hline Autoconcepto & & & & - \\
\hline
\end{tabular}

Nota: * Correlación significativa al nivel del 95\%

Ahora, al contrastar el autoconcepto en función de las conductas sexuales de los adolescentes se evidenció que existen diferencias estadísticamente significativas en el factor social entre los adolescentes que utilizaron condón en su primera relación sexual y los adolescentes que no lo utilizaron, al nivel del 95\%, es decir, que los adolescentes que utilizaron el condón en su primera relación sexual tienen un mayor autoconcepto social que los adolescentes que no lo usaron. También se encontraron diferencias significativas en el factor académico entre los adolescentes que en el último mes usaron condón en la relación sexual vaginal y los que no lo usaron, demostrando que los adolescentes que usaron el condón tuvieron un mejor autoconcepto académico que los que no los usaron. Asimismo, se evidenciaron diferencias significativas en el factor social entre los adolescentes que en el último año tuvieron relaciones sexuales sólo con la misma persona y quienes tuvieron relaciones sexuales con más de una persona, es decir, que aquellos adolescentes que sólo tienen relaciones con la misma persona tienen un autoconcepto social mucho más elevado que los adolescentes que tienen relaciones con más de una persona.

Finalmente, también se encontraron diferencias significativas en el autoconepto general entre los adolescentes que en su última relación sexual usaron el condón y quienes no lo usaron, por tanto, aquellos adolescentes que usaron el condón tienen un mayor autoconepto que los que no los usaron (Tabla 9). 
Tabla 9.

Estadísticos descriptivos para las subescalas del cuestionario de Autoconcepto Forma A en función de las conductas sexuales de los adolescentes

\begin{tabular}{|c|c|c|c|c|c|c|c|c|c|c|}
\hline & & \multicolumn{3}{|c|}{ Académico } & \multicolumn{3}{|c|}{ Social } & \multicolumn{3}{|c|}{ Emocional } \\
\hline & & M & D.T & $\mathrm{p}^{\star}$ valor & M & D.T & $\mathrm{p}^{\star}$ valor & $M$ & D.T & $\mathrm{p}^{\star}$ Valor \\
\hline \multirow{2}{*}{$\begin{array}{l}\text { Usó condón en la primera } \\
\text { relación sexual }\end{array}$} & $\mathrm{Si}$ & 23.8 & 2.1 & \multirow{2}{*}{.283} & $8.1^{*}$ & 1.5 & \multirow{2}{*}{.001} & 18.8 & 3.1 & \multirow{2}{*}{.345} \\
\hline & No & 23.4 & 2.2 & & $7.1^{*}$ & 1.2 & & 18.7 & 3.1 & \\
\hline \multirow{2}{*}{$\begin{array}{l}\text { En los últimos } 12 \text { meses } \\
\text { usó condón en la relación } \\
\text { sexual vaginal? }\end{array}$} & $\mathrm{Si}$ & $23.9^{*}$ & 2.1 & \multirow{2}{*}{.000} & 7.3 & 1.4 & \multirow{2}{*}{.536} & 18.3 & 3.3 & \multirow{2}{*}{.564} \\
\hline & No & $22.6^{\star}$ & 2.1 & & 7.5 & 1.2 & & 18.3 & 2.8 & \\
\hline \multirow{2}{*}{$\begin{array}{l}\text { En los últimos } 12 \\
\text { meses usó condón en la } \\
\text { relación sexual oral? }\end{array}$} & $\mathrm{Si}$ & 24.1 & 1.6 & \multirow{2}{*}{.553} & 8.2 & 1.4 & \multirow{2}{*}{.594} & 18.9 & 3.6 & \multirow{2}{*}{.528} \\
\hline & No & 23.8 & 2 & & 7.8 & 1.4 & & 17.9 & 2.8 & \\
\hline \multirow{2}{*}{$\begin{array}{l}\text { En los últimos } 12 \\
\text { meses usó condón en la } \\
\text { relación sexual anal? }\end{array}$} & $\mathrm{Si}$ & 23 & 2.8 & \multirow[b]{2}{*}{.325} & 8.5 & 2.1 & \multirow{2}{*}{.421} & 24 & 0 & \multirow{2}{*}{.465} \\
\hline & No & 22.5 & .7 & & 8 & 1.4 & & 18.5 & 2.1 & \\
\hline \multirow{2}{*}{$\begin{array}{l}\text { En los últimos } 12 \text { meses ha } \\
\text { tenido relaciones sexuales }\end{array}$} & $\begin{array}{l}\text { Sólo con la } \\
\text { misma persona }\end{array}$ & 23.3 & 1.8 & \multirow{2}{*}{.427} & $7.6^{\star}$ & 1.3 & \multirow{2}{*}{.000} & 18.7 & 3 & \multirow{2}{*}{.321} \\
\hline & $\begin{array}{l}\text { Con más de } \\
\text { una persona }\end{array}$ & 23.6 & 2.4 & & $7.1^{*}$ & 1.4 & & 18.4 & 3.1 & \\
\hline \multirow{2}{*}{$\begin{array}{l}\text { Usó condón en la última } \\
\text { relación sexual? }\end{array}$} & $\mathrm{Si}$ & 23.2 & 1.9 & \multirow{2}{*}{.675} & 7.7 & 1.5 & \multirow{2}{*}{.623} & 19.2 & 3 & \multirow{2}{*}{.598} \\
\hline & No & 23.3 & 2.2 & & 7.1 & 1.1 & & 18 & 2.9 & \\
\hline
\end{tabular}

\begin{tabular}{|c|c|c|c|c|c|c|c|}
\hline & & \multicolumn{3}{|c|}{ Familiar } & \multicolumn{3}{|c|}{ Autoconcepto } \\
\hline & & M & D.T. & $\mathrm{p}^{\star}$ Valor & M & D.T. & $\mathrm{p}^{\star}$ Valor \\
\hline \multirow{2}{*}{$\begin{array}{l}\text { Usó condón en la primera } \\
\text { relación sexual }\end{array}$} & $\mathrm{Si}$ & 14.8 & 2.3 & \multirow{2}{*}{.297} & 65.5 & 5.6 & \multirow{2}{*}{.189} \\
\hline & No & 14.5 & 2.2 & & 63.7 & 4.2 & \\
\hline \multirow{2}{*}{$\begin{array}{l}\text { En los últimos } 12 \text { meses } \\
\text { usó condón en la relación } \\
\text { sexual vaginal? }\end{array}$} & $\mathrm{Si}$ & 15.1 & 1.8 & \multirow{2}{*}{.528} & 64.6 & 4.5 & \multirow{2}{*}{.498} \\
\hline & No & 14 & 2.6 & & 62.4 & 4.8 & \\
\hline \multirow{2}{*}{$\begin{array}{l}\text { En los últimos } 12 \\
\text { meses usó condón en la } \\
\text { relación sexual oral? }\end{array}$} & Si & 14.3 & 2.1 & \multirow{2}{*}{.534} & 65.5 & 4.3 & \multirow{2}{*}{.523} \\
\hline & No & 14.3 & 2.3 & & 63.8 & 4.2 & \\
\hline \multirow{2}{*}{$\begin{array}{l}\text { En los últimos } 12 \\
\text { meses usó condón en la } \\
\text { relación sexual anal? }\end{array}$} & $\mathrm{Si}$ & 15.5 & .7 & \multirow{2}{*}{.386} & 71 & 5.7 & \multirow{2}{*}{.431} \\
\hline & No & 11.5 & 2.1 & & 60.5 & 2.1 & \\
\hline \multirow{2}{*}{$\begin{array}{l}\text { En los últimos } 12 \text { meses ha } \\
\text { tenido relaciones sexuales }\end{array}$} & $\begin{array}{l}\text { Sólo con la } \\
\text { misma persona }\end{array}$ & 14.4 & 2.4 & \multirow{2}{*}{.431} & 64 & 4.8 & \multirow{2}{*}{.348} \\
\hline & $\begin{array}{l}\text { Con más de } \\
\text { una persona }\end{array}$ & 14.6 & 2.2 & & 63.7 & 4 & \\
\hline \multirow{2}{*}{$\begin{array}{l}\text { Usó condón en la última } \\
\text { relación sexual? }\end{array}$} & $\mathrm{Si}$ & 14.9 & 2.3 & \multirow{2}{*}{.514} & $65.1^{*}$ & 4.5 & \multirow{2}{*}{.001} \\
\hline & No & 14.2 & 2.3 & & $62.6^{\star}$ & 4.4 & \\
\hline
\end{tabular}

Nota: * Prueba de Mann-Whitney (p-valor < .05); M: Media; D.T.: Desviación Típica 


\section{Autoeficacia de los adolescentes}

La Tabla 10 resume los estadísticos descriptivos para la Escala de Autoeficacia Generalizada. Se observa que la subescala con mayor heterogeneidad es la de autoeficacia en decir no a las relaciones sexuales, evidenciándose que algunos estudiantes sí se consideran autoeficaces para decir No a las relaciones sexuales en diferentes circunstancias, pero hay otro grupo de estudiantes que no se niegan tal fácilmente.

Tabla 10.

Estadísticos descriptivos para la escala de autoeficacia generalizada

\begin{tabular}{cccccc}
\hline & Mínimo & Máximo & Media & D.T. & CV \\
\hline $\begin{array}{c}\text { Autoeficacia en decir N0 a } \\
\text { las relaciones sexuales }\end{array}$ & 11 & 55 & 37.72 & 12.341 & $32.7 \%$ \\
$\begin{array}{c}\text { Autoeficacia en preguntar sobre } \\
\text { conductas de riesgo a su compañero }\end{array}$ & 4 & 20 & 15.67 & 4.031 & $25.7 \%$ \\
Autoeficacia en el uso del condón & 12 & 60 & 37.28 & 10.744 & $28.8 \%$ \\
Autoeficacia general & 41 & 135 & 90.66 & 22.24 & $24.5 \%$ \\
\hline
\end{tabular}

En la Tabla 11 se recogen las puntuaciones promedio y las desviaciones típicas de las escalas de Autoeficacia en función del sexo, la escolaridad y el estrato socioeconómico. Se muestra que existe una diferencia estadísticamente significativa al nivel del 95\% en la autoeficacia en decir No a las relaciones sexuales, la autoeficacia en el uso del condón y la autoeficacia en general en función del sexo, a través de la prueba no paramétrica de Mann-Whitney, por tanto, las mujeres tienen una mejor autoeficacia que los hombres, es decir, que los hombres son más susceptibles a las conductas de riesgo.

Tabla 11

Estadísticos descriptivos para la escala de Autoeficacia en función del sexo, la escolaridad y el estrato

\begin{tabular}{|c|c|c|c|c|c|c|c|c|c|c|c|c|c|}
\hline & & \multicolumn{3}{|c|}{$\begin{array}{l}\text { Autoeficacia en decir NO } \\
\text { a las relaciones sexuales }\end{array}$} & \multicolumn{3}{|c|}{$\begin{array}{l}\text { Autoeficacia en preguntar } \\
\text { sobre conductas de } \\
\text { riesgo a su compañero }\end{array}$} & \multicolumn{3}{|c|}{$\begin{array}{l}\text { Autoeficacia en el } \\
\text { uso del condón }\end{array}$} & \multicolumn{3}{|c|}{$\begin{array}{l}\text { Autoeficacia } \\
\text { General }\end{array}$} \\
\hline & & M & D.T. & $p$ & $M$ & D.T. & $p$ & $M$ & D.T. & $p$ & $M$ & D.T. & $\mathrm{p}$ \\
\hline \multirow{2}{*}{ Sexo } & Hombre & 31.9 & 10.3 & \multirow{2}{*}{.000} & 15.4 & 4.2 & \multirow{2}{*}{.639} & 34.6 & 9.5 & \multirow{2}{*}{.012} & 81.9 & 19.7 & \multirow{2}{*}{.000} \\
\hline & Mujer & 41.2 & 12.3 & & 15.8 & 4 & & 39.2 & 11.1 & & 96.3 & 22.3 & \\
\hline \multirow{2}{*}{ Escolaridad } & Décimo & 37.8 & 11.8 & \multirow{2}{*}{.772} & 16.1 & 3.5 & \multirow{2}{*}{.322} & 37.9 & 10.9 & \multirow{2}{*}{.249} & 91.7 & 21.4 & \multirow{2}{*}{.366} \\
\hline & Undécimo & 36.6 & 13.1 & & 15.1 & 4.5 & & 36 & 10.5 & & 87.7 & 22.6 & \\
\hline \multirow{3}{*}{ Estrato } & Estrato 1 & 40.5 & 10.9 & \multirow{3}{*}{.354} & 15.7 & 3.4 & \multirow{3}{*}{.153} & 37.2 & 9.4 & & 93.4 & 18.7 & \multirow{3}{*}{.830} \\
\hline & Estrato 2 & 37.4 & 12.7 & & 15.5 & 4.2 & & 37.5 & 11.3 & .926 & 90.4 & 23.9 & \\
\hline & Estrato 3 & 32 & 13 & & 19.3 & 1.2 & & 38.7 & 10.5 & & 90 & 7.8 & \\
\hline
\end{tabular}

Nota: M: Media; D.T.: Desviación Típica 
Al observar las relaciones entre las subescalas que componen la escala de autoeficacia generalizada a través del coeficiente de correlación de Spearman, se encontró una correlación significativa al nivel del 5\% entre todas las subescalas, destacándose la correlación entre la autoeficacia en decir No a las relaciones sexuales y la autoeficacia en el uso del condón (rho $=.517$ ) (Ver tabla 12).

Tabla 12

Correlaciones de Spearman entre las subescalas de la autoeficiencia

\begin{tabular}{lcccc}
\hline & 1 & 2 & 3 & 4 \\
\hline 1. Autoeficacia en decir NO a las relaciones sexuales & - & $.322^{*}$ & $.517^{*}$ & $.865^{*}$ \\
2. Autoeficacia en preguntar sobre conductas de riesgo a su compañero & - & $.439^{*}$ & $.574^{*}$ \\
3. Autoeficacia en el uso del condón & $-.853^{*}$ \\
4. Autoeficacia general & & - \\
\hline
\end{tabular}

Nota: * Correlación significativa al nivel del 95\%

Al realizar el contraste de la autoeficacia en función de las conductas sexuales de los adolescentes, se encontró que existen diferencias estadísticamente significativas en la autoeficacia entre los adolescentes que usaron condón en la relación sexual vaginal en el último año y los adolescentes que no usaron el preservativo, al nivel de significación del 5\%, por tanto, aquellos adolescentes que utilizaron condón en estas relaciones sexuales tienen una mejor autoeficacia en preguntarle a su compañero sobre conductas de riesgo y en el uso del preservativo que los estudiantes que no utilizan el condón. Entre los estudiantes que realizan relaciones sexuales bucogenitales se encontraron diferencias estadísticamente significativas en la autoeficacia en preguntar sobre conductas de riesgo a su compañero. Los que no usan condón en este tipo de relación tienden a resultar más autoeficaces en realizar preguntas a su compañero sobre su vida sexual anterior que aquellos estudiantes que sí lo usan. De otro lado, los adolescentes que en el último año han tenido relaciones sexuales sólo con la misma persona tienen una mayor autoeficacia en decir No a las relaciones sexuales bajo diferentes circunstancias, que los adolescentes que han tenido relaciones sexuales con más de una persona ( $p$-valor $=.04$ ). Finalmente, aquellos adolescentes que usaron el condón en su última relación sexual tienen una mayor autoeficacia en el uso del condón ( $p$-valor $=.01$ ). 
Tabla 13.

Estadísticos descriptivos para la escala de autoeficacia generalizada en función de las conductas sexuales de los adolescentes

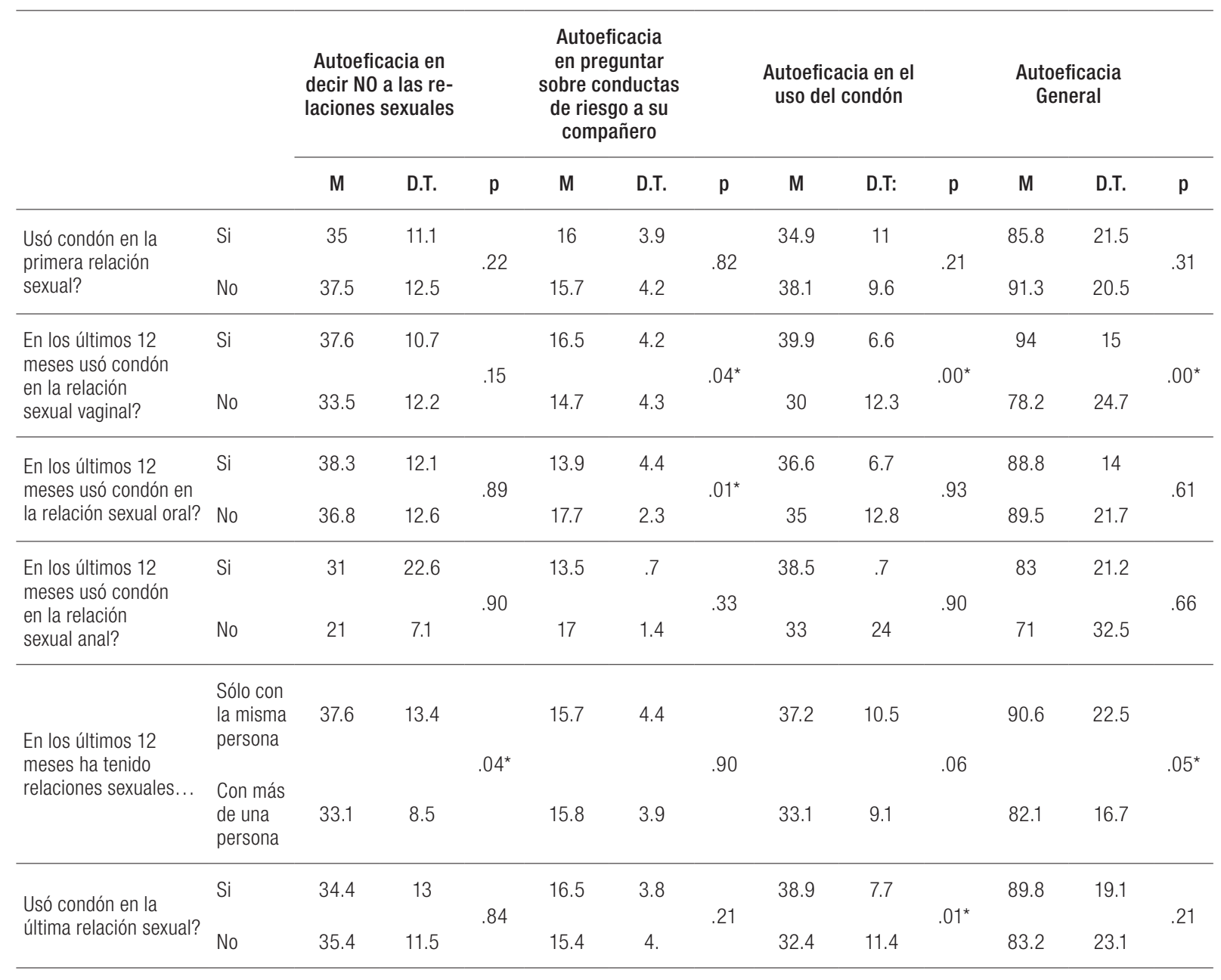

Nota: * Prueba de Mann-Whitney (p-valor < .05); Media; D.T.: Desviación Típica

Por último, la Tabla 14 muestra las correlaciones de Spearman entre las subescalas de las dos escalas aplicadas (autoconcepto y autoeficacia). Se observa que la mitad de las correlaciones resultaron significativamente diferentes de cero. La correlación más alta resultó entre la autoeficacia en el uso del condón y el autoconcepto familiar (rho $=.349$ ), lo que muestra que a un mayor autoconcepto en el factor familiar mayor será la autoeficacia en el uso del condón. Le sigue la correlación entre el factor académico del autoconcepto con la autoeficacia en general (rho = .324), al igual que el autoconcepto familiar con la autoeficacia en decir No a las relaciones sexuales en diferentes circunstancias. 
Tabla 14.

Correlaciones de Spearman entre las subescalas del cuestionario de autoconcepto y las subescalas del cuestionario de autoeficacia

\begin{tabular}{cccccc}
\hline & Académico & Social & Emocional & Familiar & Autoconcepto General \\
\hline $\begin{array}{c}\text { Autoeficacia en decir N0 a } \\
\text { las relaciones sexuales }\end{array}$ & $.313^{*}$ & .102 & -.058 & $.324^{*}$ & $.309^{*}$ \\
$\begin{array}{c}\text { Autoeficacia en preguntar sobre } \\
\text { conductas de riesgo a su compañero }\end{array}$ & .149 & -.075 & -.130 & $.197^{*}$ & .110 \\
Autoeficacia en el uso del condón & $.285^{*}$ & -.011 & -.141 & $.349^{*}$ & $.251^{*}$ \\
Autoeficacia general & $.324^{*}$ & .051 & -.132 & $.381^{*}$ & $.299^{*}$ \\
\hline
\end{tabular}

Nota: * Correlación significativa al nivel del $95 \%$

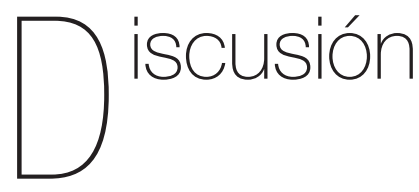

Esta investigación fue realizada teniendo en cuenta que, aunque existen diversos estudios centrados en la identificación de conductas sexuales de riesgo en la población colombiana, no se encuentran suficientes estudios en Cali que profundicen la relación con la variable autoconcepto y autoeficacia, teniendo en cuenta la importancia que tienen en la práctica sexual durante esta etapa del desarrollo. Se buscaba conocer la relación existente entre el Autoconcepto, la Autoeficacia, y las conductas sexuales de riesgo, en adolescentes escolares, con edades entre los 14 y 18 años.

En cuanto a conductas sexuales de riesgo, en la presente investigación se encontró principalmente el inicio temprano de las relaciones sexuales, el no uso del preservativo y el tener relaciones sexuales bajo el efecto de sustancias psicoactivas. Situación similar en estudios mencionados anteriormente (Antón et al., 2008; Bermúdez, Buela-Casal \& Teva, 2007), sin aun dar a conocer cuáles son las razones que están llevando a que exista una disminución en la edad de inicio de la actividad sexual. Sin embargo, hay que tener en cuenta que el porcentaje de consumo de SPA en los adolescentes del presente estudio fue superior al de estudios anteriores, probablemente este resultado se deba a las características propias del entorno social al que pertenecen.

Para el inicio de las relaciones sexuales en adolescentes, autores como Cortes et al. (2000), Campo et al. (2004), SSPM (2004), Ballester et al. (2007), Antón et al. (2008), Orcasita y Uribe (2009) y Gayet y Solís (citados por Orcasita \& Uribe, 2009), encontraron que cada vez es más precoz y que ha disminuido significativamente en las últimas décadas. Resultados similares se encontraron en esta investigación en donde la mayoría de los adolescentes han dado inicio a su vida sexual y la edad promedio se encuentra entre los 13.6 y 14 años de edad; a esto se le suma que más de la mitad no usan preservativo durante su primera relación sexual además de su no uso en los últimos 12 meses, donde se encontró que solo la mitad de los adolescentes usaron preservativo en sus relaciones sexuales. En cuanto a 
las consecuencias que pueden llegar a presentar se encuentran la exposición a embarazos a temprana edad, ITS $(\mathrm{VIH} /$ SIDA), aborto provocado y carencia de prácticas de autocuidado, así como otras situaciones que los ponen en riesgo frente a su salud, alterando el desarrollo de los adolescentes. De esta manera, cabe decir que no se trata de inhibir al adolescente frente al inicio temprano de su actividad sexual, pero sí es importante que conozca y sea consciente de los riesgos que puede tener al hacerlo sin medidas preventivas.

Continuando con el uso de métodos de protección, fue más frecuente en las mujeres que en los hombres. Así, casi la mitad de las mujeres usaron el preservativo, mientras que tan solo algunos hombres lo usaron. No se evidenció una relación significativa entre el uso del preservativo y la escolaridad. Dentro de las principales razones por las cuales no han usado el preservativo son porque confían en la persona con quien tuvieron la relación sexual, porque solo tienen relaciones sexuales con esa persona y porque a las personas con quienes tuvieron la relación les disgusta usarlo. De este modo, como ya ha sido mencionado anteriormente, el adolescente se expone a presentar consecuencias negativas para su salud cuando no conoce el pasado de la vida sexual de su pareja. Estos son aspectos importantes a considerar desde la promoción y prevención en salud sexual y reproductiva.

Este resultado se puede explicar mediante el planteamiento de autores como Enríquez et al. (2007), quienes señalan que la manera como se les trasmite el conocimiento acerca de la sexualidad es diferente para hombres y mujeres. A las mujeres se les inculca el cuidado insinuándoles que es mejor no dar inicio a las relaciones sexuales, mientras que a los hombres se les enseña que deben cuidarse de contraer enfermedades; estos aspectos guardan relación estrecha con aspectos culturales, entre ellos, los roles de género. Por su parte, Oliva, citado por Muñoz y Sánchez (2005) y Sosa (2005), presenta evidencia donde sostiene que las mujeres y hombres suelen ser criados de maneras diferentes por sus familias. A las mujeres se les inculca diferentes principios, valores y responsabilidades en cuanto a la manera de vivir su sexualidad, mientras que los hombres tienen mayor libertad para experimentar.

Así mismo, Muñoz y Sánchez (2005) señalan que las mujeres adolescentes presentan mayor conciencia frente al uso del preservativo en comparación con los hombres adolescentes, debido a que estos tienen una baja percepción de riesgo. Tal vez esta situación pueda explicarse a través del planteamiento de Jones (2010), quien dice que los diálogos que los adolescentes hombres sostienen con sus padres difieren en contenido a los que los padres tienen con adolescentes mujeres. A partir de lo anteriormente mencionado, es necesario fortalecer el diálogo y comunicación en el abordaje de la sexualidad que no solo involucre la práctica sexual genital, sino los aspectos afectivos que hacen parte de ella.

En este sentido, el diálogo y discursos que permean los padres con las adolescentes se da con énfasis en la idea de poder quedar embarazada, recomendando que lo mejor sea la abstinencia o, en caso de mantener relaciones sexuales, se les aconseja que sea por amor y con el novio, discursos que divergen con las prácticas 
y actitudes de los adolescentes frente a su sexualidad (Jones, 2010), mientras que al hombre sólo se le manifiesta que puede tener relaciones sexuales si usa preservativo. Siguiendo por la misma línea, Andrade et al. (2006) señalan que los hombres son más propensos a tener relaciones sexuales con parejas ocasionales, en comparación con las mujeres que suelen tener relaciones sexuales con la pareja estable. En el caso de éstas, aquellas que tienen un vínculo de apego y mantienen comunicación con sus padres son las que tienen menor probabilidad a dar inicio a su vida sexual, al contrario de lo que sucede con los hombres, ya que los que tienen buenas relaciones con sus padres son quienes presentan el mayor número de relaciones sexuales. Éste fue otro aspecto clave encontrado en la investigación con relación al autoconcepto familiar, lo que conduce a pensar que, si bien la información sola no es suficiente para tomar conductas protectoras, de alguna manera puede lograr que el adolescente manifieste lo que está pensando y se le oriente mejor para tomar mejores conductas protectoras cuando se tiene una buena relación y confianza con los adultos que le rodean, ya sean padres o maestros.

Otro resultado obtenido en la investigación que se puede explicar teniendo en cuenta el planteamiento anterior es el número de parejas sexuales, ya que los participantes de la investigación reportan que en los últimos 12 meses el 40.3\% de los adolescentes estudiados han tenido relaciones sexuales con más de una persona. Este porcentaje es superior en los hombres que en las mujeres, es decir, los hombres tienen una mayor probabilidad de tener relaciones sexuales en el último año con más de una persona. Sin embargo, cabe aclarar que este resultado no determina que los adolescentes se cuiden en todas y cada una de sus relaciones. Esto se puede relacionar con lo que plantean diferentes autores que sugieren que la manera de criar a los hombres, en cuanto al ejercicio de su sexualidad, difiere completamente del estilo de crianza de las mujeres, ya que a los hombres se les orienta de una manera más permisiva con la posibilidad de ejercer su sexualidad libremente y sin represiones (Andrade et al., 2006)

Otro factor de riesgo que influye en las conductas sexuales de riesgo es el consumo de sustancias psicoactivas (SPA), el cual incrementa el deseo sexual y los jóvenes, al tener relaciones sexuales bajo sus efectos, disminuyen la percepción de riesgo e interfiere en el autoconcepto y la autoeficacia, haciendo que, por ejemplo, en varias ocasiones no usen anticonceptivos (Barona et al., 2009), un uso compartido de agujas, consumo de alcohol y otras drogas que disminuyen las inhibiciones sexuales y alteran la capacidad de juicio (Cortés et al., 2000). Para este estudio, más de la mitad de los adolescentes que han tenido relaciones sexuales en los últimos 12 meses con penetración del pene, lo han hecho bajo el efecto de alguna sustancia, siendo un resultado superior a los de anteriores investigaciones. De este grupo de adolescentes, la mayoría ha estado bajo el efecto del alcohol, marihuana, heroína y el consumo de bazuco, tranquilizantes, pastillas alucinógenas, pegante o inhalantes.

Con relación a la identificación de los niveles de autoeficacia y autoconcepto en la muestra poblacional del estudio, se encontró relación entre el género masculino y el autoconcepto académico, 
reafirmando la postura de otros autores como Amezcua \& Pichardo (2000). Se observa que el factor emocional se relaciona positivamente con el factor familiar, sin embargo, la relación es débil, es decir, que a un mayor autoconcepto familiar mayor será el autoconcepto emocional. De otro lado también se encontró una relación estadísticamente significativa entre el factor académico, el factor social, el factor emocional y el factor familiar, todos con el autoconcepto en general. Hay que tener en cuenta el planteamiento de autores que comprobaron que el autoconcepto académico y familiar incide significativa y positivamente sobre la adscripción de una concreta orientación a meta (González, 2002, citados por Álvarez et al., 2003); de esta manera, aquellos estudiantes que obtienen mayor rendimiento en las diferentes áreas académicas son quienes finalmente obtienen un mejor comportamiento frente a su sexualidad.

Por otra parte, respecto a la autoeficacia, se evidenció que algunos estudiantes se consideran autoeficaces para decir no a las relaciones sexuales en diferentes circunstancias, pero hay otro grupo de estudiantes que no se niegan tan fácilmente. Las mujeres tienen una mejor autoeficacia que los hombres, es decir, los hombres son más susceptibles a las conductas de riesgo. Se destaca la correlación entre la autoeficacia en decir no a las relaciones sexuales y la autoeficacia en el uso del condón, lo que lleva a pensar que el adolescente, al estar emitiendo dichas conductas protectoras, está probablemente pensando en los beneficios para su salud. La autoeficacia es considerada una variable de gran interés en los procesos relacionados con la salud sexual de las personas por los beneficios que proporcionan las estrategias de autocuidado.
Se considera que es primordial en la reducción de riesgo frente a la infección por VIH y también para la evaluación en la prevención de la misma (Uribe, 2005; Barona et al., 2009). En cuanto al tercer objetivo específico que consintió en establecer correlaciones entre autoeficacia, autoconcepto y conductas sexuales de riesgo en función de variables sociodemográficas se puede establecer que sí hubo correlaciones entre las variables, específicamente con relación al sexo.

Con respecto a las correlaciones encontradas se identificó que en la variable autoconcepto, al contrastar en función de las conductas sexuales de los adolescentes, se evidenció que existen diferencias estadísticamente significativas en el factor social entre los adolescentes que utilizaron condón en su primera relación sexual y los adolescentes que no lo utilizaron, es decir, que los adolescentes que utilizaron el condón en su primera relación sexual tienen un mayor autoconcepto social que los adolescentes que no hicieron uso del mismo. También se encontraron diferencias significativas en el factor académico entre los adolescentes que en el último mes usaron condón en la relación sexual vaginal y los que no lo usaron, mostrando así que los adolescentes que usaron el condón tuvieron un mejor autoconcepto académico que los que no los usaron. Se encontraron diferencias significativas respecto al factor social entre los adolescentes que en el último año tuvieron relaciones sexuales sólo con la misma persona y quienes tuvieron relaciones sexuales con más de una persona, es decir, que aquellos adolescentes que solo tuvieron relaciones con la misma persona tienen un autoconcepto social mucho más elevado que los adolescentes que las tuvieron con más de una persona. Finalmente, 
también se encontraron diferencias significativas en el autoconcepto general entre los adolescentes que en su última relación sexual usaron el condón y quienes no lo usaron, por tanto, aquellos adolescentes que usaron el condón tienen un mayor autoconcepto que los que no los usaron.

Estos resultados permiten reafirmar los resultados de anteriores investigaciones tales como Goñi et al. (2006), quienes concluyeron que el autoconcepto positivo va de la mano con hábitos de vida saludables; o los resultados de Balaguer et al. (2006), donde destacan que los jóvenes con bajo autoconcepto realizan comportamientos de riesgo para la salud. En su investigación, Antón et al. (2008), señalaron que el autoconcepto media en la toma de decisiones afectando y contribuyendo a la adopción de conductas de riesgo sexuales. De esta manera, se puede establecer que aquellos estudiantes pertenecientes a la población investigada que tienen conductas protectoras frente al ejercicio de su sexualidad son quienes presentan un mayor autoconcepto y autoeficacia. Esto demuestra que no es suficiente con educación e información frente al ejercicio de la sexualidad, sino que, además, se deben fortalecer estos aspectos psicosociales.

En cuanto a la autoeficacia, al realizar el contraste en función de las conductas sexuales de los adolescentes, se encontró que existen diferencias estadísticamente significativas en la autoeficacia entre los adolescentes que usaron condón en la relación sexual vaginal en el último año y los adolescentes que no usaron el preservativo, por tanto, aquellos adolescentes que utilizaron condón en estas relaciones sexuales tienen una mejor autoeficacia en preguntarle a su compañero sobre conductas de riesgo y en el uso de preservativo que los estudiantes que no lo usaron. Entre los estudiantes que realizan relaciones sexuales bucogenitales se encontraron diferencias estadísticamente significativas en la autoeficacia en preguntar sobre conductas de riesgo a su compañero. Los que no usan condón en este tipo de relación resultan más autoeficaces al realizar preguntas a su compañero sobre su vida sexual anterior que aquellos que sí lo usan. Por otro lado, los adolescentes que en el último año han tenido relaciones sexuales sólo con la misma persona tienen una mayor autoeficacia en decir No a las relaciones sexuales bajo diferentes circunstancias, que los adolescentes que han tenido relaciones sexuales con más de una persona.

Finalmente, aquellos adolescentes que usaron el condón en su última relación sexual tienen mayor autoeficacia en el uso del condón. Así, se corroboran los resultados de diferentes investigaciones en donde se establece que la conducta sexual de riego está influenciada por predictores o variables psicosociales tales como los conocimientos, las creencias y la autoeficacia. Del mismo modo, el uso inconsistente del condón tiene como predictores variables psicosociales como la autoeficacia y el autoconcepto (Corrales et al., 2008; López \& Moral, 1999; Moreno et al., 2006).

En conclusión, cuanto mayor autoconcepto en el factor familiar se evidencie mayor será la autoeficacia en el uso del condón. Además, se destaca la correlación entre el factor académico del autoconcepto con la autoeficacia en general, al igual que el autoconcepto familiar con la autoeficacia en decir No a las relaciones sexuales en diferentes circunstancias. Por 
ello, se puede afirmar que el autoconcepto funciona como factor protector para evitar conductas que puedan ser perjudiciales para la salud del individuo en caso de adolescentes y como el motor que impulsa al individuo a la búsqueda de comportamientos que beneficien su salud. Teniendo en cuenta lo anterior, se reafirma que la autoeficacia y el autoconcepto son variables que influyen beneficiosamente en los comportamientos sexuales de los adolescentes, debido a que su componente emocional y de motivación impulsan a los individuos a adoptar conductas en beneficio de la salud tal y como lo habían manifestado anteriores investigaciones (Balaguer et al., 2006; Corrales et al., 2008; Gálvez et al., 2005). En este orden de ideas, se demuestra que tanto el autoconcepto como la autoeficacia son factores que influencian la conducta de un individuo y lo llevan o no a tomar medidas preventivas para su salud, en este caso, protegerse de las conductas sexuales de riesgo debido a que se comprobó que aquellos adolescentes que tienen fortalecidos ambos aspectos son quienes tienen menos probabilidad de incurrir en conductas sexuales de riesgo.

Como recomendaciones para futuras investigaciones se hace necesario continuar investigando de manera cualitativa con el fin de profundizar en el por qué el autoconcepto y la autoeficacia funcionan como factores protectores frente a las conductas sexuales de riesgo. Además de hacer una relación de estas variables con otras como la función familiar y características propias de la población. También se recomienda continuar indagando sobre el autoconcepto académico y su relación con las conductas sexuales de riesgo, así como realizar estudios en poblaciones con menores edades, dado al inicio cada vez más temprano de las relaciones sexuales.

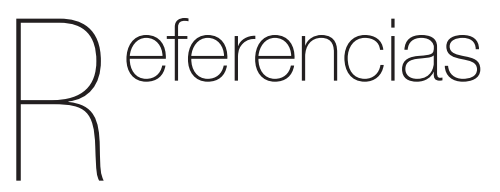

Alcalá, G., Alonso, L., Consuegra, A., Lubo, A., \& Pérez, M. (2007). Comportamiento de riesgo para la salud en estudiantes colombianos recién ingresados a una universidad privada en Barranquilla (Colombia). Salud Uninorte, 24, 235-247.

Alcántara, J. (1995). Cómo educar la autoestima. España: Ediciones Ceac.

Álvarez, L. Bernardo, A. Cabanach, R. Roces, C. González, J. González, P. González, S. Muñiz, R. Núñez, J. Rodríguez, S. \& Valle, A. (2003). Adaptabilidad y cohesión familiar, implicación parental en conductas autorregulatorias, autoconcepto del estudiante y rendimiento académico. Psicothema, 15, 471-477.

Amezcua, J. \& Pichardo, C. (2000). Diferencias de género en autoconcepto en sujetos adolescentes. Anales de Psicología, 16, 207-214.

Andrade, P., Betancourt, D. \& Palacios, J. (2006). Factores Familiares asociados a la conducta sexual en adolescentes. Revista Colombiana de Psicología, 15, 91-101.

Antón, R. \& Espada, J. (2009). Consumo de sustancias y conductas sexuales de riesgo para la transmisión del VIH en una muestra de estudiantes universitarios. Anales de Psicología, 2, 444-350. 
Antón, F., Espada, J. \& Soledad, M. (2008). Autoconcepto y búsqueda en sensaciones como predictores de las Conductas sexuales bajo los efectos de las drogas en universitarios. Salud y Drogas, 8(2), 137-135.

Argote, L., Castillo, E., Mejía, M., Vásquez, M. \& Villaquirán, M. (2005). La educación y el ejercicio responsable de la sexualidad en adolescentes. Colombia Médica, 36, 33-42.

Balaguer, I., García, M. \& Pastor, Y. (2006). Relaciones entre el Autoconcepto y es estilo de vida saludable en la adolescencia media: un modelo exploratorio. Psicothema, 18, 18-24.

Ballester, R., Gaviria, A., Gil, M., Quiceno, J., Soto, A. \& Vinaccia, S. (2007). Conductas sexuales de riesgo para la infección por $\mathrm{VIH} / \mathrm{SIDA}$ en adolescentes colombianos. Terapia Psicológica, 25, 39-50.

Bandura, A. (1977). Self- efficacy: toward a unifying theory of behavioral change. Psychological review, 84, 191-215.

Bandura, A. (1987). Pensamiento y acción fundamentos sociales. Barcelona: Martínez Roco.

Bandura, A. (1999). Ejercicio de la eficacia personal y colectiva en sociedades cambiantes en Auto-Eficacia: Cómo afrontamos los cambios de la sociedad actual. (pp. 19-54). Bilbao: Desclée de Brouwer.

Barona, C., Uribe, A., \& Vergara, T. (2009). Susceptibilidad y Autoeficacia frente al $\mathrm{VIH} /$ Sida en adolescentes de Cali-Colombia. Revista Latinoamericana de Ciencias Sociales, Niñez y Juventud, 7(2), 1513-1533.
Bermúdez, M., Buela-Casal, G., \& Teva, I. (2007). Variables sociodemográficas y conductas de riesgo en la infección por el VIH y las enfermedades de transmisión sexual en adolescentes. Revista Española de Salud Pública, 83, 309-320.

Bermúdez, J., Pérez, A., \& Suarez, P. (2000). Escala de Autoeficacia general: datos psicométricos de la adaptación para población española. Psicothema, 12, 509-513.

Bojanini, J., y Gómez, J. (2004). Resultados obstétricos y perinatales en adolescentes. Revista Colombiana de Obstetricia y Ginecología, 55, 114-121.

Campo, A., Castillo, M., Meneses, M., Navarrete, P., \& Silva, J. (2004). Factores asociados con el inicio temprano de relaciones sexuales en estudiantes adolescentes de un colegio de Bucaramanga, Colombia. Revista Colombiana de Psiquiatría, 33, 367-377.

Castellá, J., Carlotto, M., \& Gonçalves, S. (2007). Predictores de conductas Sexuales de Riesgo entre adolescentes. Revista Interamericana de Psicología, 41, 161-166.

Corrales, A., Piña, J., \& Rivera. (2008). Variables psicológicas como predictores de conductas de prevención relacionadas con la infección por VIH. Colombia Médica, 39, 17-23.

Cortes, A., García, R., Fuentes, J., Monterrey, P., \& Pérez, D. (2000). Sida, Adolescencia y Riesgos. Revista Cubana de Medicina General Integral, 16, 253-260.

Encuesta Nacional de Demografía y Salud [ENDS]. (2010). Salud Sexualy Reproductiva en Colombia. Profamilia. 
Enríquez, C., Guevara, E., Latorre, S., Nieto, O., Pacheco, C., \& Rincón, J. (2007). Significaciones de la sexualidad y salud reproductiva en adolescentes de Bogotá. Salud Pública, 49(1), 45-51.

Feijoo, A (2004). Trends in Sexual Risk Behaviors among High School Students-U.S., 1991 to 1997 and 1999 to 2003. Recuperado de http://www.advocatesforyouth.org/index. php?option=com_content\&task=view\&id= 459\&ltemid=336.

García, F., \& Musitu, G. (1995). Autoconcepto Forma 5. AF5. Madrid: TEA, Ediciones.

Gómez, C. (2009). Impacto de la Presencia de Docentes, Padres y Madres en un Programa de Educación Sexual dirigido a los y las Adolescentes de la Localidad de los Mártires en Bogotá. Típica, Boletín Electrónico de Salud Escolar, 5(1), 20-31.

Goñi, A., Rodríguez, A., \& Ruiz de Azua, S. (2006). Autoconcepto físico y estilos de vida en la adolescencia. Intervención Psicosocial, 15(1), 81-94.

Hernández, R., Fernández, C., \& Baptista, P. (2006). Metodología de la investigación. México DF: McGraw-Hill Interamericana.

Jerusalem, M. \& Schwarzer, R. (1992). Selfefficacy as a resource factor in stress appraisal processes. En R. Schwarzer (Ed.): Self-efficacy: Thought control of action. (pp. 195-213). Washington, DC: Hemisphere.

Jones, D. (2010). Diálogos entre padres y adolescentes sobre sexualidad: discursos morales y médicos en la reproducción de las desigualdades de género. Interface, 14, 171-181.
León, O., \& Montero, I. (2005). Sistema de clasificación del método en los informes de investigación en psicología. Revista Internacional de Psicología Clínica y de la Salud, 5, 115-127.

Ministerio de Salud de Colombia. (1997). CCVSA. Cuestionario Confidencial sobre Vida Sexual Activa. Bogotá: Ministerio de Salud de Colombia.

Moreno B., Garrosa, E. \& Gálvez, M. (2005). Personalidad positiva y salud. En L. FlorezAlarcon, M. Mercedes \& B. Moreno (2005) Psicología de la salud. Temas actuales de investigación en Latinoamérica. (pp. 59-76) Bogotá: ALAPSA.

Moreno, D., Piña, J., y Robles, S. (2006). Determinantes del uso inconsistente del condón en mujeres que tienen sexo vaginal, oral y anal. Anales de Psicología, 22, 200-204.

Muñoz, A. \& Sánchez, M. (2005). Influencia de de padres y amigos sobre la actitud hacia las conductas sexuales de prevención en la adolescencia un análisis en función de género. Revista Latinoamericana de Psicología, 37, 71-79.

Mruk, C. (1999). Autoestima: investigación, teoría y práctica. España: Editorial Desclée De Brower, S.A.

Orcasita, L. \& Uribe, A. (2009). Conductas sexuales de riesgo en estudiantes universitarios de la ciudad de CaliColombia. Revista Virtual Universidad Católica del Norte, 27, 1-31.

Organización Mundial para la Salud. (2011). Salud y desarrollo del niño y del adolescente. Recuperado de http://www. 
who.int/maternal_child_adolescent/topics/ adolescence/dev/es/

Sánchez, J. (2006). Efectos delarepresentación del mensaje para realizar conductas saludables: el papel de la Autoeficacia y de la motivación cognitiva. International Journal of Clinical and Health Psychology, 6, 613-630.

Secretaría de Salud Pública Municipal (2004). Estudio sobre conocimientos, actitudes y prácticas de la sexualidad en la población de Cali. Cali: Secretaria de Salud Pública Municipal.

Sosa, I. (2005). Más allá del eterno femenino. Significaciones de la salud y la sexualidad de los jóvenes. Cuernavaca: Instituto Nacional de las Mujeres.
Uribe, A., Vergara, T., \& Barona, C. (2009). Susceptibilidad y autoeficacia frente al $\mathrm{VIH} /$ Sida en adolescentes de Cali-Colombia. Revista latinoamericana, 7, 1513-153.

Uribe, F. (2005). Evaluación de Factores Psicosociales de riesgo parala infección por VIH/SIDA en adolescentes colombianos. (Tesis Doctoral). Universidad de Granada, España.

Urquijo, S. (2002). Autoconceto y desempeño académico en adolescentes. Relaciones con sexo, edad e institución. Psico-USF, 7, 211-218.

World Association For Sexual Health. (2005). Declaración de Montreal "Salud Sexual para el Milenio" XVII Congreso Mundial de Sexología. Montreal. Canadá 